\title{
POR UMA ABORDAGEM ECOLÓGICA DA LINGUAGEM
}

\section{Paulo Henrique Duque (UFRN)}

\begin{abstract}
RESUMO: Neste artigo, pretendo especificar como um tipo particular de conhecimento sobre o mundo (affordances) interage com um tipo específico de conhecimento linguístico (construções) para produzir significado. Para isso, identificarei alguns processos envolvidos nessa integração, alguns tipos de combinação possíveis e algumas consequências semânticas dessas combinações, adotando o mecanismo de indexação proposto por Glenberg e Robertson (1999), de acordo com o qual, a compreensão de enunciados engloba três procedimentos: indexação, derivação e combinação de affordances, com base em restrições físicas e biológicas, bem como restrições sintáticas fornecidas pela sentença. À medida que a cognição se desenvolve na interação organismo-ambiente, a maneira como semantizamos o mundo depende sobremaneira dos recursos biológicos e físicos fornecidos pelo ecossistema do qual fazemos parte. Integrados ao ecossistema, gerenciamos inputs, percebemos, reconhecemos e associamos entidades em tempo real e, assim, aliviamos nossas memórias. Diante disso, a integração da estrutura conceptual (conceitos) com a estrutura material (física, do ambiente, e biológica, do organismo) parece ser uma estratégia cognitiva fundamental.

PALAVRAS-CHAVE: Cognição Ecológica; Semântica Cognitiva; Gramática de Construção.
\end{abstract}

\section{FOR AN ECOLOGICAL APPROACH TO LANGUAGE}

\begin{abstract}
The paper specifies how a particular kind of knowledge about the world (affordances) interacts with a specific type of linguistic knowledge (buildings) to afford meaning. To account for that, I'll identify some processes involved such integration, some types of potential blends and some semantic consequences from such combinations. I will embrace indexing mechanism proposed by Glenberg and Robertson (1999), according to which, understanding of utterances encompasses three procedures: indexing, derivation and blending of affordances, events based on physical and biological constraints and syntactic constraints provided by the sentence. As the cognition develops on the organismenvironment interaction, how we assign meaning to the world depends on greatly the biological and physical resources provided by the ecosystem to which we belong. Integrated ecosystem, we manage inputs, we perceive, we recognize and we associate entities on the fly and thereby we relieve charge of our memories. Therefore, the integration of the conceptual framework with the material structure (physical, environmental, and biological, of the body) appears to be a critical cognitive strategy.

KEYWORDS: Ecological Cognition; Cognitive Semantics; Construction Grammar.
\end{abstract}

\section{INTRODUÇÃO}

Dentro de uma perspectiva em que a cognição se desenvolve na interação organismoambiente, a maneira como atribuímos sentidos ao mundo depende sobremaneira dos recursos biológicos e físicos fornecidos pelo ecossistema do qual fazemos parte. Integrados ao ecossistema, gerenciamos inputs, percebemos, reconhecemos e associamos entidades em tempo real e, assim, aliviamos nossas memórias. Nesse sentido, a cognição se distribui por todo o ecos- 
sistema. Essa cognição distribuída, dinâmica e complexa, é organizada graças à linguagem, que estabelece a conexão entre pessoas em si e entre pessoas, recursos ecológicos e tradições. A linguagem emerge quando falamos, fazemos gestos, manipulamos e imaginamos objetos e instituições sociais.

À medida que nossas interações configuram a maneira como construímos significados e desenvolvemos habilidades de enriquecer pensamentos e de refinar ações, a linguagem não deve ser concebida como um objeto autônomo. Por fazemos parte de uma rede social dinâmica, a experiência linguística pode alterar quem somos quando orientamos o outro (e o outro nos orienta). Buscamos a sincronia com o outro, criando expectativas, rastreando olhares e evocando memórias. Enfim, a linguagem conecta o aqui e o agora com o que já foi e, crucialmente, com o que está por vir. Portanto, a linguagem também é um fenômeno distribuído.

Dentro dessa visão ecológica, as redes neurais garantem certa estabilidade e rapidez aos processos cognitivos que dependem de informações perceptuais e motoras não presentes. Nesses casos, informações linguísticas contribuem para a recuperação de imagéticas de ações e das partes do corpo que as executam, por meio da ativação de áreas do córtex motor e prémotor envolvidas na produção de ações motoras dessas mesmas partes do corpo (cf.: BERGEN; HEEYON, 2010, p. 969). Esse mecanismo de simulação mental ${ }^{1}$ foi evidenciado em um experimento que verificou como entendemos alguns verbos (HAUK; JOHNSRUDE; PULVERMÜLLER, 2004). Os resultados reveleram que os verbos indexam ações específicas (realizadas por diferentes efetores ${ }^{2}$ ) processadas em diferentes regiões do córtex pré-motor. As áreas envolvidas no movimento das pernas, por exemplo, se tornam mais ativas durante o processamento de itens linguísticos relacionados a pernas (p. ex., chutar, andar e pular) do que durante o processamento de itens relacionados a outras partes do corpo (p. ex., pegar, segurar e escrever). Além disso, informações perceptuais sobre a natureza dos objetos manipulados, dos agentes e dos cenário da ação influenciam na precisão do processamento.

1 De acordo com Bergen e Chang (2005), a simulação mental corresponde ao acionamento interno de sistemas cerebrais para criar ou recriar experiência não presentes. A simulação mental pode ser visual, no que se refere às partes do sistema visual que ficam ativas de maneira semelhante ao modo como reagiríamos se um estímulo externo estivesse realmente presente, ou pode ser motora, no que se refere à ativação de partes do cérebro dedicadas ao controle motor como modelo de ação física, usualmente sem relmente acionar músculos.

2 Os efetores, constituídos de músculos e glândulas, são órgãos que recebem estímulos do Sistema Nervoso Central e atuam sobre um sistema muscular ou glandular já existente na anatomia humana (ou específica de cada espécie). A disponibilidade e características específicas dos órgãos efetores é que determinam o tipo de reação do sistema muscular ou glandular aos estímulos do Sistema Nervoso Central. 
Diante disso, parece que a integração da estrutura conceptual (conceitos) com a estrutura material (física, do ambiente, e biológica, do organismo) é uma estratégia cognitiva fundamental. Neste artigo, pretendo caracterizar alguns processos envolvidos nessa integração; tipos de combinação possíveis; e consequências semânticas dessas associações. Para isso, em primeiro lugar, descrevo a proposta de Glenberg e Robertson (1999), de acordo com a qual, a compreensão de sentenças envolve três procedimentos: indexação de palavras a referentes; derivação das affordances ${ }^{3}$ (GIBSON, 1979) desses referentes, e combinação (meshing) dessas affordances, com base em restrições físicas e biológicas, bem como restrições sintáticas fornecedidas pela sentença. Para concluir, argumento que conceitos abstratos também podem ser compreendidos em termos de experiências ecologicamente situadas.

\section{INDEXAÇÃO LEXICAL E SIMULAÇÃO MENTAL}

De acordo com a Hipótese Indexical, adaptada aqui de Glenberg \& Robertson (1999), a compreensão linguisticamente guiada aciona a simulação da ação e do deslocamento físico por meio de três procedimentos: 1) palavras e expressões linguísticas mais amplas são indexadas a corpos físicos do ambiente de entorno ou à imagética desses corpos, quando estes não estão presentes; 2) dos corpos físicos do ambiente, extraímos affordances; e 3) as affordances (e não as palavras) restringem a maneira como as idéias podem ser coerentemente combinadas.

Quanto à hipótese da simulação, Glenberg e Kaschak (2002) realizaram um experimento para verificar o tempo de resposta dos participantes ao compreenderem sentenças que descreviam a transferência de objetos concretos, tais como (01) e (02).

(01) Andy entregou a pizza para você.

(02) Você entregou a pizza para Andy.

Assim que terminasse a leitura de cada sentença, o participante deveria pressionar um botão para que fosse exibida, no monitor, a frase seguinte. Os pesquisadores verificaram que o intervalo de tempo entre a leitura da frase e o pressionamento do botão foi menor, quando o

\footnotetext{
3 Segundo Gibson (1986), o verbo to afford (fornecer) é encontrado no dicionário, mas o substantivo affordance não. $\mathrm{O}$ autor deu significado próprio ao termo. O termo passou a designar as possibilidades oferecidas pelo ambiente a um agente particular. Nesse sentido, superfícies possibilitam locomoção, alguns objetos possibilitam manuseio e alguns animais possibilitam interação. Assim, quando um agente percebe superfícies, objetos e animais, ele percebe affordances.
} 
tipo de transferência descrito indicava movimento para fora, exemplo (02). Com esse resultado, os autores concluíram que o processamento cognitivo da transferência interfere no movimento de transferência em si, o que parece evidenciar o compartilhamento de circuitos neurais.

\section{MODELOS MODAIS E AMODAIS}

Os modelos amodais ${ }^{4}$ dependem de um grande número de proposições a fim de modelar a compreensão de eventos simples. Em outras palavras, é preciso representar, por exemplo, o significado de 'apontar' por meio de um símbolo amodal. Nessa perspectiva, APONTAR não apresentaria nenhuma conexão com os sistemas perceptual e motor. Em vez disso, sua forma seria completamente arbitrária - apenas um símbolo. Uma coisa que sabemos sobre um símbolo como esse é que ele teria de ser relativamente complexo, uma vez que o ato de apontar necessariamente envolve dois participantes, AQUELE QUE APONTA e A COISA APONTADA. Nesse sentido, a notação de APONTAR seria apresentada como em (03).

(03) apontar [aquele que aponta, coisa apontada]

A notação apresentada em (03) não sinaliza nenhum envolvimento dos recursos motores ou perceptuais do corpo e físicos do ambiente. O símbolo, nesse caso, sugere uma relação meramente representativa de uma ação realizada no mundo: a de apontar. De acordo com Bergen (2012), uma forma de se ilustrar o funcionamento da representação amodal é imaginando como seria o comando, em linguagem de programação, que guiasse as ações de um agente autômato. Em tal linguagem, poderia existir, por exemplo, o comando-z representando a ação de apontar. O autor esclarece que, por ser amodal, um comando como esse estaria isolado dos mecanismos de controle dos movimentos do autômato e, consequentemente, de recursos fundamentais que lhe permitiriam realizar, por exemplo, o reconhecimento de objetos e eventos. Assim, teríamos de programar o comando-z para que o robô executasse a ação de apontar quando algum objeto fosse posicionado no seu entorno. $\mathrm{O}$ comando seria algo como (04).

4 De acordo com esses modelos, a compreensão envolve apenas representações internas do mundo. Essa perspectiva é denominada amodal porque não prevê a correlação entre conteúdos de percepção ou de movimento relacionados às respectivas modalidades perceptuais e motoras. 
(04) se

próximo (objeto, robô)

então

comando-z (objeto, braço mecânico) ${ }^{5}$.

O comando-z, relatado em (04), só seria relevante em função das ações que o robô pudesse realizar. No entanto, apesar de esse comando estar fortemente relacionado com a percepção (trata do reconhecimento de um objeto) e com uma ação motora (apontar o objeto reconhecido), ele continuaria sendo amodal, pois não estaria vinculado fisicamente nem a sensores nem a mecanismos de movimento do robô. Tratar-se-ia simplesmente de um símbolo, uma vez que se limitaria meramente a espelhar um evento do mundo, o de apontar, de forma totalmente arbitrária. Em outras palavras, o evento de apontar estaria sendo "representado" pelo símbolo comando-z e não por outro símbolo qualquer, como comando-y ou comando-w. Se a linguagem é uma representação amodal do mundo, então, quando ouvimos ou lemos um enunciado sobre APONTAR precisamos ativar um símbolo amodal, como comando-z. Nesse caso, não é preciso simular a ação de apontar porque o próprio símbolo codifica um espécie de significado essencial da palavra "apontar" realizando a representação mental correspondente a APONTAR no mundo.

Não há dúvidas de que essa solução é elegante e econômica. No entanto, como apontam os resultados de alguns experimentos demonstrando que informações motoras e perceptuais relacionadas à forma e à orientação dos objetos são necessárias durante o processamento da linguagem (STANFIELD; ZWAAN, 2001; ZWAAN et al., 2002; BORODITSKY, 2000 e FINCHER-KIEFER, 2001, GLENBERG; KASCHAK, 2002), palavras estão vinculadas aos objetos do mundo de alguma forma, de modo que o processo de indexação parece estabelecer o conteúdo acerca do que (ou de quem) se está falando. Nesse sentido, a compreensão de um enunciado, como (05), a meu ver, exige, dentre outras coisas, a construção do significado de "apontar".

(05) Ao usar uma bússola para identificar pontos de referência, um passo é apontar a seta de orientação em direção a um lugar determinado.

De acordo com a perspectiva que defendo aqui, o modo como alguém aponta para alguma coisa (ou alguém) depende, em parte, das affordances do objeto para o qual se aponta e da parte do corpo envolvida na ação de apontar, os olhos, o braço, a mão e o dedo indicador, ou da ferramenta utilizada com esse intuito, no caso, uma bússola. Sendo assim, apontar com

5 Leia-se: se um objeto se encontra próximo do robô, então deve-se executar o comando-z, ou seja, apontar o braço mecânico para o objeto. 
o dedo indicador ou com a seta de direção de uma bússola orientam a construção de significados distintos, uma vez que essas duas possibilidades mobilizam a indexação de palavras a objetos, utilizando (ou não) ferramentas, que disponibilizam affordances bem específicas. Para a compreensão de (05), as dimensões, o peso, o modo de segurar e o mecanismo de funcionamento de uma bússola nos leva a simular uma das várias formas de se apontar para alguma coisa ou para alguma direção.

Um experimento conduzido por Zwaan (1999) demonstrou que, ao lerem sobre uma manobra de montain bike, pessoas sem experiência em ciclismo construíram modelos mentais sem o detalhamento mínimo necessário para a execução da manobra, ao passo que os leitores com experiências no esporte foram capazes de realizar uma compreensão bastante detalhada, envolvendo informações proprioceptivas, motoras, somestésicas e ópticas. Dentro de uma visão ecológica de cognição, é relevante considerarmos a maneira como nos relacionamos com o segmento ambiental (nicho ecológico) e como affordances são identificadas.

\section{RELAÇÃO ORGANISMO-AMBIENTE IDENTIFICAÇÃO DE AFFORDANCES}

Em grande medida, a linguagem humana é sobre as coisas do mundo. Nós facilmente nos referimos a objetos usando palavras como "abridor", "abridor de garrafas" ou "aquela coisa branca de abrir garrafas que eu lhe emprestei ontem durante a festa". Esse relacionamento entre palavras e mundo, normalmente chamado de "referência", tem sido objeto de muitas hipóteses e discussões. Muitas teorias e abordagens postulam a existência de uma etapa intermediária entre palavras e mundo, normalmente rotulada de "conceito". No entanto, essa noção varia até mesmo em questões fundamentais como: um conceito é uma construção mental do usuário da língua ou uma entidade independente, abstrata? Há dois procedimentos que precisam ser considerados quando abordamos a noção de conceito: a caracterização da estrutura interna (se ela existe) do conceito e a explicação de como essa estrutura se relaciona com o mundo. Em muitos casos, as teorias focalizam o primeiro procedimento e negligenciam ou dão uma resposta vaga para o segundo.

Somos autônomos no modo de interagir com o segmento ambiental em que estamos inseridos e desenvolvemos conceitos pessoais sobre isso. Não tentamos internalizar uma representação completa do mundo, nem mantemos cristalizados todos os possíveis conceitos herdados da nossa comunidade linguística. Se quiséssemos construir uma máquina que usasse 
a linguagem da mesma forma que um humano, esse artefato precisaria apresentar o mesmo tipo de autonomia humana: ser capaz de construir seus próprios conceitos a partir de experiências sensório-motoras e sociais. Essa máquina dependeria do seu nicho ecológico e social para manter a estabilidade de parte dos significados em geral. A necessidade desse tipo de autonomia é evidente: um robô que se locomove não pode ser considerado um "robô que se locomove" se precisar ser transportado para se locomover. Com relação à dimensão linguística, essa limitação é geralmente aceita: são os seres humanos que fornecem os dados de input e a interpretação do output às máquinas, eliminando a possibilidade de elas próprias desevolverem qualquer tipo de intencionalidade.

Outra falha bastante comum é pensarmos que um artefato conectando palavras umas às outras esteja fazendo uso de uma língua, mesmo dependendo dos seres humanos para estabelecer qualquer tipo de significado às suas palavras. Isso não é apenas uma falha do uso linguístico por máquinas. São as teorias sobre conceptualização que nos induzem a esse erro. Há boas razões para construirmos robôs que caminham: configuramos nosso ambiente para ser favorável a nossa locomoção, por isso, se um robô quer compartilhar esse ambiente, deve aprender a andar como um ser humano. O mesmo deveria valer para a linguagem: podem até existir maneiras facilmente implementáveis de as máquinas produzirem arremedos de linguagem sem a exigência de que tal produção esteja vinculada a um ecossistema, mas se pretendemos construir máquinas que usem a linguagem humana de verdade, os conceitos e as intencionalidades devem ser do mesmo tipo e qualidade dos conceitos e intencionalidades humanas. A ausência de uma integração entre a estrutura linguística e um entorno ambiental e social apenas convém a teorias que negligenciam o cárter intencional dos conceitos. Embora as teorias que definam palavras em termos de outras palavras sejam predominantes, se queremos construir uma máquina que use a linguagem de todas as maneiras que o ser humano é capaz, precisamos recomeçar do zero, adotando uma abordagem que considere a intencionalidade e a interação, mediada ou não, entre agente e ambiente, como crucial para a formação de conceitos e concepções. Qualquer teoria que separe o agente do ambiente e o agente de outros agentes está fadada a lidar, não com conceitos, mas com definições destituídas de qualquer sopro de vida, pois um conceito só pode ser apreendido e aprendido e compreendido nas relações intersubjetivas que pavimentam nossos nichos ecológicos.

Essa visão ecológica de cognição e linguagem parece estar em sintonia com a necessidade de considerarmos a relação intencional entre agente e segmento ambiental. A interação, portanto, é o foco principal de uma perspectiva ecológica de cognição. A linguagem 
parece estar fortemente fundamentada no aqui e no agora perceptual, em processos sociais e sensório-motores que constituem sistemas abertos, capazes de identificar e resolver uma variedade infinita de tarefas em tempo real. Enquanto parte de um sistema de compartilhamento de foco, a linguagem é continuamente guiada por uma variedade de atos comunicativos locais que a mantém estabilizada.

Uma noção que tem inviabilizado a visão ecológica de cognição é a ideia de que existe um profundo abismo entre o mundo como ele realmente é e o mundo como nós o percebemos. Essa suposição em si não seria tão problemática caso não fosse a implicação inevitável de seus dois pressupostos: a) a pobreza do estímulo, isto é, a noção de que a informação disponível aos nossos sentidos é irremediavelmente fragmentada, limitada e insuficiente para especificar as propriedades e eventos do mundo real; b) a pobreza do mundo real, isto é, grande parte do que nós experienciamos e que parece pertencer ao mundo real não é real. Apresenta um carácter puramente subjetivo, não passando de uma projeção mental de um mundo inerentemente sem cor e sem sentido.

De acordo com Gibson (1977), qualquer substância, superfície ou arranjo tem affordances. O problema central dessa teoria é se a informação está realmente disponível durante a percepção dessas affordances. O autor enquadra a questão das affordances em termos de percepção e não de ação. No entanto, é na atuação que descobrimos, revelamos ou até mesmo criamos o que elas realmente proporcionam. Outro problema é que, ao longo dos anos, Gibson chegou a definir affordances em termos de "percepção direta" (e de "percepção literal"), em oposição a uma ampla variedade de exemplos que ele mesmo considerou como sendo de percepção indireta, isto é, a percepção de ilustrações e fotografias, os estereótipos sociais e o uso de microscópios e telescópios. Muitos desses exemplos de percepção indireta envolvem a mediação social. Os críticos da afirmação de Gibson de que affordances podem ser percebidas diretamente observaram que as affordances de artefatos humanos não podem ser determinadas por alguém que desconheça tais artefatos e esteja isolado de outras pessoas.

A limitação do conceito de affordances é que, embora sejam relacionais, sua relação se restringe ao binômio agente-objeto. A affordance não se limita a um objeto isolado, mas depende de uma coleção de objetos relacionados e de eventos. Em especial, as affordances de artefatos não costumam ser autônomas. Elas dependem de um contexto mais amplo que envolve outros artefatos e um conjunto de ações envolvendo tais objetos. De acordo com Costall e Dreier (2006, p. 11), 
[...] as coisas são compreendidas melhor [...] não como estáticas e independentes das pessoas, mas transformadas em si mesmas, ainda por vir, dentro de práticas em andamento, as quais esses objetos, por sua vez, transformam. Nós [...] aprendemos mais sobre as pessoas e as coisas estudando-as como parte do mundo, não apenas como estando no mundo, mas como incorporadas dentro das práticas do mundo ${ }^{6}$.

Cumpre esclarecer que, entendidas como aspectos da constituição física do mundo em parte socialmente construídas, affordances são compatíveis com a proposta cognitiva apesar de terem sido rejeitadas por Lakoff (1987, p. 215) no domínio da Linguística cognitiva. Segundo o autor,

Gibson reforçou a importância da interação constante de seres humanos com, e enquanto parte inseparável de, seus ambientes. Nossas visões em relação a propriedades interacionais e corporalidade se integram com a de Gibson sobre esta questão. $\mathrm{O}$ insight de Gibson aqui é de grande importância ${ }^{7}$.

E continua o autor

Mas o trabalho de Gibson é sobre percepção, não sobre cognição. E há um aspecto da psicologia da percepção de Gibson que parece não se estender à cognição. Gibson distinguiu entre realidade física e ambiente. A realidade física é independente de todos os seres animados. O ambiente é definido em relação a como os seres podem interagir com ele. Dessa forma, árvores, por exemplo, são subíveis. Gibson chama essas oportunidades de interação fornecidas pelo ambiente de affordances ${ }^{8}$.

Cumpre esclarecer que o foco de Lakoff está direcionado para a definição referencialista externa de affordances (visão inicial de Gibson). A redefinição apresentada aqui (e implícita em parte da literatura sobre affordances) contraria completamente essa definição. O processo de identificar affordances de objetos linguisticamente já indexados pressupõe que todas as possibilidades de interação de um indivíduo com esses objetos reflete diversas maneiras de interagir (e diversas intenções de interação) com esses objetos num dado espaço e num dado momento. Quanto às affordances a serem identificadas, por exemplo, as do objeto caixa, se uma pessoa precisa usá-la como um recipiente de livros, a affordance ENCHER X COM Y vai ser identificada mais facilmente, ao passo que, se uma pessoa quer usá-la como suporte, a affordance DISPOR Y SOBRE X vai ser identificada mais facilmente.

6 "Things are best understood [...] not as fixed and independent of people, but as themselves transformed, even coming into being, within ongoing practices, and which these objects, in turn, transform. We [...] learn more about both people and things by studying them as worldly, not just as in the world, but as incorporated into practices in the world".

7 "Gibson stressed the importance of the constant interaction of human beings with, and as an inseparable part of, their environments. Our views concerning interactional properties and embodiment mesh with Gibson's on this issue. Gibson's insight here is of the greatest importance".

8 "But Gibson's work on perception, not on cognition. And there is an aspect of Gibson's psychology of perception that appears not to extend to cognition. Gibson distinguished between physical reality and the environment. Phisical reality is independent of all animate beings. The environment is defined relative to how beings can interact with it. Thus, trees, for example, are climp-up-able. Gibson speaks of such opportunities for interaction provided by the environment as affordances". 


\section{COMBINAÇÃO DE $A F F O R D A N C E S$ E RESTRIÇÕES SINTÁTICAS}

Como vimos, no processo de compreensão de enunciados, as affordances não ocorrem isoladamente umas das outras. Elas são combinadas por restrições fornecidas pelos próprios objetos e pela sintaxe. Esse dois tipos de restrição contribuem para a criação de padrões de ação direcionados a objetivos específicos. A estrutura do objeto caixa de papelão, por exemplo, permite enchê-la ou dispor coisas na sua superfície. Essas possíveis ações envolvendo o objeto podem ser combinadas com outras ações, tais como usar a caixa como suporte para um jogo de cartas. Em outras palavras, ao combinarmos as affordances de caixa de papelão, de suporte e de jogo de cartas, compreendemos uma sentença como (06).

(06) Os homens estão jogando cartas numa caixa de papelão.

Por outro lado, ao combinarmos as affordances de caixa, de contêiner e de livros, compreendemos uma sentença como (07).

(07) O professor colocou o livro numa caixa de papelão.

Cumpre ressaltar que a noção de combinação aqui pode ser pensada em termos de blending (cf.: FAUCONNIER e TURNER, 2002), desde que esse processo possa englobar restrições biológicas e físicas. A dificuldade de estabelecermos certas combinações é que torna a compreensão de enunciados como (08) extremamente difícil.

(08) Os homens quebraram as barras de ferro numa caixa de papelão (?).

Em (08), compreendemos a caixa como sendo um contêiner, pois as affordances de caixas de papelão não combinam com a ação de quebrar barras de ferro, devido a sua estrutura frágil e flexível. Além das restrições físicas dos objetos, a sintaxe da sentença também fornece limitações à combinação. A forma de uma sentença fornece pistas do evento geral que está sendo descrito. Um evento de transferência, por exemplo, atribui relevância a certas affordances e, sobretudo, fornece instruções para que a combinação seja concretizada, de modo que todos os objetos e pessoas envolvidos sejam dispostos numa relação direta uns com os outros.

Em (06) e (07), a configuração sintática restringe o modo como a combinação das affordances pode ser realizada: a posição, com a abertura para cima ou com a abertura para baixo, e o modo como a caixa é manipulada, como recipiente ou como superfície, 
respectivamente. Naqueles exemplos, é impossível compreendermos o enunciado numa perspectiva em que a caixa esteja manipulando pessoas. O papel da estrutra sintática na configuração das possibilidade de combinação das affordances de objetos distintos exige a adoção de uma concepção de gramática que possibilite a integração, em seu escopo, das noções até aqui apresentadas. Acredito que a GCC possa cumprir esse papel.

\section{GRAMÁTICA DE CONSTRUÇÃO CORPORIFICADA ${ }^{9}$}

A Gramática de Construção (GC) foi estimulada pelo desenvolvimento da Semântica Cognitiva, com início em 1975, e se estendeu pela década de 1980. O artigo de Lakoff (1977), "Gestalts Linguistics" (Chicago Linguistic Society) foi uma versão inicial da GC, postulando que o sentido do todo não era uma função da composição do significado das partes. Em vez disso, o autor sugeriu que as construções acionavam significados próprios.

O desenvolvimento da GC ocorreu na década de 1980, conduzido por Charles J. Fillmore, Kay Paul e George Lakoff, com a finalidade de explicar casos que, intrinsecamente, ultrapassavam a capacidade da gramática gerativa. O primeiro trabalho, "There-Constructions", apareceu como um estudo de caso em "Women, Fire, and Dangerous Things", de George Lakoff (1987). Nesse estudo, o autor demonstrou que o significado do todo não era a soma dos significados das partes; que propriedades gramaticais específicas da construção dêitica "there" se originavam do significado pragmático da construção; e que as variações encontradas na construção central poderiam ser entendidas como simples extensões de uma construção central.

O artigo de Fillmore et al. (1988) sobre a construção "let alone" foi o segundo clássico sobre o assunto. Esses dois trabalhos conduziram a Linguística Cognitiva ao estudo da GC. O aspecto formal da construção é tipicamente descrito como um modelo de sintaxe, mas a forma não abrange apenas a sintaxe. Envolve, além disso, aspectos de fonologia, como prosódia e entonação, bem como o significado semântico e pragmático.

9 O rótulo "Gramática de Construção" abrange uma família de teorias ou modelos de gramática que se baseiam na idéia de que a unidade básica da gramática é a construção gramatical em vez de regras que organizam unidades isoladas. $\mathrm{Na}$ perspectiva da GC, a gramática de uma língua é composta de taxonomias de famílias de construções. 
Uma construção gramatical, independentemente da sua complexidade formal e semântica e da sua composição, é um pareamento de forma e significado. Os estudiosos da abordagem construcional defendem que todos os pareamentos de forma e significado são construções gramaticais, incluindo padrões discursivos (cf.: DUQUE e COSTA, 2011), sentenças, expressões idiomáticas, palavras, morfemas e fonastemas. Ao contrário do modelo componencial, a GC nega qualquer distinção rigorosa entre léxico e sintaxe e propõe um continuum. Tanto a palavra quanto a construção gramatical complexa são pareamentos de forma e significado e diferem apenas na complexidade interna. Em vez de serem módulos discretos e, portanto, sujeitos a processos, formam os extremos de um continuum.

De acordo com Evans, Bergen e Zinken (2007), a língua pode ser caracterizada como constituída de um conjunto de camadas de organizações distintas — a estrutura do som, o conjunto de palavras compostas por esses sons, as estruturas sintáticas constituídas por essas palavras etc. Os autores utilizam a metáfora da torta para explicar a maneira como essas camadas são organizadas, ou seja, uma sobre a outra. As abordagens modulares cortam o bolo horizontamente tomando camada por camada para estudá-las internamente. Em outra direção, a abordagem da GC corta a fatia do bolo verticalmente, ou seja, ao tomar uma fatia vertical, apreende todas as camadas da língua: fonologia, morfologia, sintaxe e “[...] uma vigorosa cobertura semântica"10 (p. 4). De acordo com os autores (p. 4),

Uma fatia vertical de língua é necessariamente mais complexa em alguns aspectos do que uma fatia horizontal - ela é mais variada e texturizada - mas, ao mesmo tempo, possibilita possíveis explanações que não estão disponíveis em uma perspectiva modular, horizontal ${ }^{11}$.

Apesar de a noção de pareamento nos fornecer um aparato teórico interessante para o entendimento de como especificações de sentido são orientadas por construções sintáticas particulares, há muito mistério em torno de como o pareamento forma-significado é construído. Com esse intuito, muitas teorias foram propostas. Uma dessas teorias, a Gramática de Construção Corporificada (GCC), desenvolvida por Bergen e Chang (2005), com o objetivo de compreender o modo como agentes (humanos ou não) adquirem e usam a língua, foi inspirada em noções oriundas da linguística computacional, da linguística cognitiva, da inteligência artificial e da psicologia do desenvolvimento. De acordo com essa perspectiva corpori-

10 “[...] a healthy dollop of semantics on top".

11 "A vertical slice of language is necessarily more complex in some ways than a horizontal one — it is more varied and textured — but at the same time it aff ords possible explanations that are simply unavailable from a horizontal, modular perspective". 
ficada, durante o processo de compreensão, o leitor/ouvinte utiliza a construção linguística para atribuir sentido ao mundo, ativando várias estruturas conceptuais inter-relacionadas e, durante o processo de produção, o falante/escritor constrói padrões linguísticos que expressam suas intenções comunicativas.

A GCC se diferencia de outras propostas construcionais por ajustar o foco na maneira como construções favorecem a comunicação, ou seja, por se tratar de uma perspectiva orientada-para-o-processo. Nesse sentido, para a GCC, não é suficiente especificar o pareamento forma/significado. É necessário investigar o modo como esses pareamentos interagem com o conhecimento de mundo e com o ambiente para suportar o uso linguístico. Para isso, devemos caracterizar forma e significado como esquemas de forma e de significado, respectivamente. Nesse caso, os esquemas de forma fornecem informação relevante para a superfície (p. ex. cadeias fonológicas ou gráficas associadas, informação entonacional, ordenação temporal etc.), enquanto os esquemas de significado ajudam a especificar parâmetros para "simulações mentais"12 (BARSALOU, 1999).

Acredito que é por meio dessas simulações que se torna possivel a integração, reivindicada pela abordagem ecológica, entre informações linguísticas, informações perceptuais e motoras e circuitos neurais. Em outras palavras, a linguagem explora grande parte das mesmas redes neurais acionadas na ação, percepção, imaginação, memória e outros processos fundamentados neuralmente. As estruturas linguísticas definem parâmetros para as simulações que, por sua vez, recorrem à ativação e acionamento de circuitos neurais. Sendo assim, os defensores da hipótese da simulação percebem uma nítida relação entre as estruturas linguísticas — construções - e outros processos cognitivos e sensório-motores. Tomemos como exemplo a sentença (14).

(14) O doutor sentou-se numa pedra.

Em (14), há algumas pistas de superfície diretamente acessíveis ao destinatário e algumas inferências que podem ser extraídas dessas pistas. Suponhamos que a sentença seja segmentada em palavras (“O”, “doutor”, “sentou”, “se”, “em”, “uma”, “pedra”) e seja observada a ordem em que elas aparecem. Poderíamos também incluir alguma indicação do contorno entonacional, uma vez que, na forma escrita, a sentença termina com um ponto, sugerindo um contorno neutro ou declarativo para a sua contraparte falada. Com base nesse conjunto limita-

12 "Mental simulations". 
do de pistas de superfície, é possível inferirmos que o evento SENTAR-SE aconteceu em algum momento anterior ao da fala; que quem se sentou é um indivíduo apresentado como “doutor” (por padrão, um humano do sexo masculino); e que há vários motivos para alguém se sentar (por padrão, para descansar).

Outras inferências podem também ser acessadas, apesar de potencialmente menos relevantes: a personagem presumivelmente tem pernas, gasta energia para flexionar suas pernas, e estava de pé, possivelmente caminhando, antes de parar e se sentar. Essas inferências não são especificamente linguísticas, mas dependem principalmente do conhecimento geral sobre "pessoas que se sentam" e eventos que envolvem "o ato de se sentar". Além disso, as inferências são subordinadas a contextos interpretativos específicos (isto é, à restrição de que "doutor" caracterize um médico, um advogado, alguém que tenha obtido um título de doutorado etc.) que podem alterar as referências mais prováveis desses usos, o relacionamento inferido entre eles e a natureza do movimento de sentar-se.

\section{INTEGRAÇÃO ENTRE A HIPÓTESE INDEXAL E A GCC}

Nesta seção, pretendo integrar a perspectiva de construções aos três procedimentos usados na compreensão da linguagem, propostos por Glenberg e Robertson (1999). Em (15), por exemplo, os elementos indexados por crianças, caixa e sala são integrados em um modelo cognitivo.

(15) As crianças empurraram a caixa para fora da sala.

Quando as affordances são acionadas por "crianças" e "caixa", o processo de combinação tem início. À medida que a sentença é lida/ouvida, as affordances vão sendo combinadas em uma simulação do evento relatado. A gramática atua em todos esses estágios ajudando no processo de indexação fornecendo restrições sobre como a simulação deve funcionar.

Alterações em qualquer um desses processos, como uma mudança na estrutura sintática da sentença, por exemplo, resultaria numa alteração da simulação a fim de acomodar as mudanças. Grande parte dessa operação é realizada no próprio contexto discursivo, isto é, “crianças", "caixa" e "sala" já podem ter sido indexados em uma etapa anterior do discurso. 
Em geral, se as affordances não puderem ser combinadas da forma orientada pela sintaxe (empurrar uma caixa com um barbante, por exemplo), a compreensão é prejudicada.

Esse processo de simulação proporcionado pela integração entre construções e affordances envolve também as experiências de controle motor. Por exemplo, de acordo com Bergen (2012), ao pensarmos em que direção giramos a maçaneta de uma porta, normalmente criamos uma imagem visual do movimento da mão girando a maçaneta. Ao realizar esse exercício simples de simulação, alguns chegam a refazer o movimento mimicamente. Durante esse exercício, fazemos mais do que apenas evocar imagens visuais: imaginamos também a força adequada a ser aplicada e refletimos sobre o sentido do giro da mão em torno do pulso (horário ou anti-horário?). Ao imaginar diferentes objetos, simulamos diferentes forças. Bergen e Wheeler (2005) denominam a construção mental dessas rotinas motoras de simulação motora.

De acordo com os autores, a simulação perceptual e motora é a criação de experiências mentais de percepção e de ação na ausência de sua manifestação externa. Em outras palavras, somos capazes de reproduzir a experiência de ver alguma coisa ou ouvir um som (ou ruído) sem que o estímulo esteja sendo captado pelo nosso campo visual/auditivo. Além disso, somos capazes de reproduzir a experiência de executar uma ação mesmo que o movimento não esteja acontecendo de fato. Essas experiências de simulação são sentidas qualitativamente como percepções reais: as cores, por exemplo, são simuladas da mesma maneira como as cores diretamente percebidas e as ações são simuladas da mesma maneira que são sentidas quando são executadas.

Da mesma forma que as outras funções cognitivas, a linguagem depende dessas simulações mentais. Enquanto ouvimos (ou lemos) frases, simulamos mentalmente a visão de cenas e a realização das ações que estão sendo descritas. Incrivelmente, as simulações mentais, realizadas durante a compreensão da linguagem, podem ser bem detalhadas. Observemos o exemplo (16).

(16) Antes de esticar o arame-farpado, o homem enfiou os moirões na terra.

Alguns experimentos (cf.: AZIZ-ZADEH et al., 2006; BERGEN; WHEELER, 2010) evienciaram que, para compreender sentenças como essa, simulamos ações como ENFIAR. Para compreender esse enunciado, simulamos as affordances dos objetos mencionados: os 
moirões estão numa posição perpendicular ao chão. Simulamos as cores e formatos dos objetos: moirões são estacas grossas que devem ser parcialmente enterradas no chão.

Exemplos como esse contribuem para reforçar a ideia de que simulamos percepções e ações. Mas o que há na linguagem que nos possibilita a realização dessas simulações mentais com propriedades tão específicas? Parte da resposta a essa pergunta está na própria seleção lexical. Substantivos como 'homem' e 'moirões' acionam tipos de experiências que podem ser simuladas perceptualmente, já formas verbais como 'enfiou' acionam simulações de ações motoras. A seleção lexical é apenas parte da explicação, uma vez que, para que haja a simulação mental do conteúdo integral de um enunciado, os elementos perceptuais e motores acionados pelas palavras devem ser combinados apropriadamente: o homem está enfiando "o moirão na terra", não "a terra no moirão". Enquanto as palavras de uma sentença sinalizam quais tipos de experiência devemos simular mentalmente (homens, moirões, terra etc) e suas affordances, a gramática nos orienta como organizar tais experiências numa simulação, isto é, a gramática coloca as palavras em ordens específicas caracterizando-as de modos particulares.

Nesse sentido, simulamos cenas diferentes quando nos deparamos com:

(17) O homem enfiou o moirão na terra.

(18) O moirão enfiou o homem na terra.

As simulações das sentenças (17) e (18) são diferentes, não por causa da diferença entre as palavras em si, uma vez que os termos são os mesmos nas duas sentenças (“o", "homem”, “enfiou”, “o”, "moirão", "na”, "terra”). O que causa essa diferença é principalmente a ordenação dos termos. A ordem gramaticalmente determinada é de importância crucial para a simulação, ou seja, é papel da gramática juntar as contribuições que as palavras individuais trazem para a simulação.

Cabe enfatizar, no entanto, que restringir o papel da gramática à ordenação das palavras numa frase não é novidade nos estudos linguísticos. Em suas definições, a tradição gramatical sempre atribuiu à gramática uma função de ordenação, como o conjunto de regras e princípios que determinam a ordenação de palavras numa sentença. A noção de simulação mental revela que a gramática faz mais do que simplesmente combinar palavras individuais em uma dada sequência ordenada. A gramática exerce outras funções adicionais. De acordo com Bergen (2012): 
a) A gramática contribui para a simulação mental, fornecendo-lhe conteúdos reais. Observe as sentenças a seguir:

(19) Conca lançou a bola para Washington.

(20) O advogado mostrou o processo para o cliente.

As sentenças (19) e (20) compartilham a mesma organização gramatical, ou seja, são bitransitivas. Em cada uma delas, há uma ação (LANÇOU e MOSTROU), seguida por um objeto físico (BOLA e PROCESSO) e um agente (WASHINGTON e CLIENTE). Logo, a estrutura transitiva em questão compreende uma ação, um objeto e uma pessoa. O que é relevante em sentenças que apresentam essa estrutura é que, enquanto simulamos mentalmente as cenas que elas descrevem, identificamos alguém que transfere um objeto de sua posse para um recipiente. Por exemplo, em (19), Conca agiu de forma a fazer com que Washington recebesse a bola. De onde esse significado de transferência vem?

Sabemos que esse significado de transferência não vem das palavras individuais, pois há muitas formas de lançar sem que haja uma transferência de coisas (lançar um produto, lançar um alerta, lançar a nota no diário de classe etc.), já o jogador Conca é capaz de executar outras tarefas que não sejam a de transferir coisas. Nesse enquadre, o significado de TRANSFERÊNCIA não parece ser acionado pelas palavras em si, mas pela estrutura gramatical da sentença como um todo. Ao serem organizadas em padrões como o apresentado nos exemplos (19) e (20), essas construções acionam o significado de transferência de posse. Portanto, além de ordenar palavras, a gramática em si acrescenta restrições de significado ao processo de simulação.

b) Além de ordenar e ajudar na semantização, as estruturas gramaticais contribuem para a simulação mental de uma outra maneira: além de um enunciado indicar o que simular, a gramática deixa evidente como simular. Quando realizamos a simulação visual, adotamos uma perspectiva particular - a de um agente realizando uma ação, a de um agente para quem (ou o que) uma ação é realizada, ou a de um observador externo. As palavras presentes em uma sentença, por si, normalmente não restringem as perspectivas a serem adotadas. Mas a construção gramatical compensa essa carência atribuindo algumas instruções. Por exemplo, você adota a perspectiva de primeira pessoa quando lê o exemplo (21).

(21) Eu estou lendo este artigo.

Mas adota a perspectiva de terceira pessoa quando lê o exemplo (22). 
(22) O laptop está sobre a mesa.

Nesse sentido, a gramática direciona a perspectiva a ser adotada durante a realização de uma simulação. Nos últimos anos, houve uma ampliação da pesquisa sobre simulação mental no processo de compreensão da linguagem. Com isso, vem sendo cada vez mais aceita a ideia de que as pessoas realizam inconscientemente muitas imagens mentais perceptuais e motoras dos conteúdos dos enunciados. As palavras contribuem, mas é a construção gramatical que reúne e orienta a simulação.

Um questionamento que pode ser feito à perspectiva ecológica é se a noção de affordances conjugada com a da GCC pode ser estendida ao tratamento de conceitos mais abstratos.

\section{CONCEITOS MAIS ABSTRATOS}

Lakoff (1987) defende que a imagética inicial (esquema imagéticos, para o autor) pode se estender metaforicamente a domínios mais abstratos. Dentro desse enquadre, a noção de CONTÊINER, por exemplo, é esquematizada com base na experiência direta de que um contêiner apresenta um dentro e um fora e que um objeto pode estar dentro ou fora de outro, mas nunca dentro e fora ao mesmo tempo (ver DUQUE, 2015). Essa percepção direta de contêineres e de suas affordances seria a base, de acordo com o autor, para a nossa compreensão de um princípio lógico estruturado como “p ou não-p, mas não ambos". Na visão de Barsalou (1999), a simulação é criada a partir de situações experienciadas no cotidiano que, com o tempo, vão sendo refinadas pela linguagem. Sendo assim, a noção de contêiner emergiria da experiência com exemplos específicos de recipientes, ou seja, usamos a linguagem baseados em situações concretas nas quais affordances são identificadas. Nesse sentido, pode ser que a abstração emerja de múltiplos exemplos. O conceito de DEMOCRACIA, por exemplo, parece emergir, em grande parte, de experiências específicas (em primeira ou terceira pessoa) envolvendo o ato de votar.

É claro que uma compreensão mais sofisticada da noção de "democracia" envolve muito mais do que isso. No entanto, essa sofisticação parece estar baseada em exemplares múltiplos, da mesma forma que a compreensão sofisticada sobre CADEIRA inclui CADEIRAS DE JANTAR, CADEIRAS ESTOFADAS, CADEIRAS DE BALANÇO etc. Em 
suma, a compreensão de idéias abstratas tem relação com o uso de exemplos concretos em todos os níveis de aprendizagem. Mas como isso ocorre?

Como vimos acima, o ser humano aciona seus sistemas perceptuais e motores durante o processo de compreensão linguística sobre coisas que vê ou ouve. Nesse processo, as pistas linguísticas parecem orientar as simulações. Uma característica da informação linguística, que a diferencia de outras informações perceptuais, é que podemos usá-la para tratar de coisas e ações não-percebidas e não-executadas no ambiente de entorno de quem fala e ouve. Mas que simulações mentais estariam sendo produzidas por indexadores linguísticos como "amor", "solidão" e "sociedade"? Como será que compreendemos enunciados como (23)?

\section{(23) Vocês vão ter que me engolir!}

Tudo indica que, em (23), nossos sistemas motor e perceptual não estão em jogo durante a compreensão. Indexadores linguísticos como esses - sobre conceitos abstratos — apresentam um obstáculo para a noção de que compreensão é simulação. Como podemos acionar simulações mentais a partir de enunciados sobre coisas que não parecem ser capturadas pelos órgãos sensoriais?

Para verificar como ocorre a compreensão de sentenças sobre conceitos abstratos, selecionei algumas ocorrências de palavras que nos remetem a noções intangíveis fisicamente, como SOCIEDADE. Para entender como as pessoas usam o item linguístico "sociedade", utilizei o mecanismo de busca Google e verifiquei como elas falam de sociedade.

(24) Entre os mecanismos alienantes da economia e as limitações opressoras do poder, o Homem reage infiltrando, nas fendas da sociedade, formas de vivencias revitalizadoras para recuperar seu sentido de participação e construção de identidade (http://www.plurall.com, em 06/10/2011).

(25) Atualmente a nossa sociedade se abriu para uma grande discussão no âmbito educacional (www.webartigos.com, em 06/10/2011).

(26) Sempre presentes na história da humanidade, as epidemias continuam a interferir no comportamento das pessoas, trazendo medo e preconceito para dentro da sociedade (psiquecienciaevida.uol.com.br, em 06/10/2011).

Apesar de não termos noção de como a sociedade é fisicamente, que cheiro tem ou que som emite, somos capazes de compreender os enunciados (24), (25) e (26). Ao analisar mais detidamente os trechos selecionados, verifiquei que o modo como (24), (25) e (26) se referem à sociedade é semelhante ao modo como falamos de coisas concretas: que possuem fendas por onde passam coisas; que podem ser abertas e onde objetos podem ser introduzidos. Mesmo sem uma análise mais profunda, esses exemplos evidenciam que tratamos a sociedade como 
se ela fosse uma espécie de recipiente que possui "fendas", que pode "ser aberto" e que tem “um interior”, onde podemos “depositar coisas”. Em minha rápida investigação, identifiquei outras maneiras de compreender sociedade. Sociedade pode ser um corpo, como em (27), (28) e (29).

(27) O arroz representava a espinha dorsal econômica da sociedade samurai (www.aikikai.org.br, em 06/11/2011).

(28) Hoje, o que mutila a sociedade é a desagregação da família e o enfraquecimento dos seus valores (www.psdc.org.br, em 06/11/2011).

(29) Esse video que estou postando junto é de uma banda que gosto muito, e mostra as mentes e os braços da sociedade (sociologiass-unesp. blogspot.com, em 06/11/2011).

O uso sistemático de enunciados que normalmente descrevem uma coisa concreta (como um recipiente ou o corpo) para descrever uma coisa abstrata (como SOCIEDADE) é conhecido como metáfora. Por exemplo, em "trazendo medo e preconceito para dentro da sociedade" alguma coisa se move para dentro de um recipiente, por meio de uma abertura. Isso nos leva a simular um movimento físico descrito pelo enunciado. Em outras palavras, realizamos simulações motoras e perceptuais mesmo quando processamos enunciados metafóricos.

Para Bergen (2012), tudo indica que as simulações mentais realizadas quando compreendemos enunciados metafóricos devem ser menos detalhadas que as construídas durante o processamento de enunciados concretos. Apesar disso, com a linguagem metafórica temos, pelo menos, um indicador claro de que coisas concretas estão sendo simuladas mentalmente, o que viabiliza a identificação de affordances. No entanto, há enunciados sobre conceitos abstratos que não especificam coisas concretas. Comparemos os exemplos (30) e (31).

(30) O preço no mercado de usados despencou e ficou mais fácil comprar um super esportivo nos Estados Unidos (http://www.boss568.com, em 06/10/2011).

(31) Além do novo design, o 307 tem um novo motor e o melhor: o preço diminuiu (www.santander.com.br, em 06/10/2011).

Há uma diferença sutil entre a senteça metafórica (30) e a sentença abstrata (31): o verbo 'cair' nos leva a simular TRAJETÓRIA, enquanto o verbo 'diminuir' não nos indica qualquer movimento no espaço. Sendo assim, como compreendemos enunciados abstratos como o apresentado em (31)? Segundo Bergen, também compreendemos conceitos abstratos como coisas concretas, mesmo que a conexão entre abstrato e concreto não esteja explícita em uma dada sentença. Compreendemos "o preço diminuiu", em (31), do mesmo jeito que "o preço despencou", em (30), simulando um movimento para baixo. Como não há especificação de qual domínio concreto é acionado durante a simulação, pode haver uma variação maior no 
domínio concreto usado para compreender o conceito abstrato. É possível simularmos preços diminuindo em termos de VOLUME, QUANTIDADE e/ou VERTICALIDADE.

Compreendemos enunciados abstratos não apenas relacionando-os com algum domínio concreto distante, mas também com objetos e eventos concretos que estão diretamente vinculados a eles. Basicamente, simulamos mentalmente coisas e eventos concretos que acompanham o conceito abstrato. Nesse sentido, se lemos/ouvimos pistas como "o preço diminuiu", podemos muito bem simular uma CAIXA REGISTRADORA, um CORRETOR DA BOLSA ou ALGUÉM REMARCANDO O PREÇO DE UM PRODUTO e combinar as affordances dessas entidades e eventos.

\section{CONCLUSÃO: COGNIÇÃO PARA ALÉM DOS CÉREBROS E CORPOS}

A cognição se estende para alem dos nossos cérebros e corpos! Tentei mostrar aqui que visões comuns sobre cognição e linguagem não são capazes de fornecer elementos para expicar a relação entre linguagem, cérebro e ambiente. O principal problema é que concebem a linguagem como uma forma de operar o sistema nervoso em vez de investigarem o que nos torna excelentes modeladores de significados. Ao adotarmos uma visão ecológica de cognição, torna-se impossível dar conta da cognição sem considerar as várias maneiras como nos integramos aos nossos nichos ecológicos. Dentro dessa visão, a linguagem deixa de ser concebida como um conjunto de símbolos abstratos localizados na cabeça e passa a ser compreendida como uma atividade comportamental modelada pelos acasos da vida, mas que sustenta a unidade do sistema organismo-ambiente em suas interações complexas e dinâmicas. É claro que a abordagem aqui defendida precisa de uma agenda de revisão de pressupostos cognitivistas há muito assumidos e não questionados, a fim de avançarmos na elaboração de uma hipótese ecológica de cognição em que linguagem, cérebro e ambiente sejam vistos como partes de um todo irredutível a entidades autônomas, de modo que essas entidades só possam ser compreendidas se houver uma adequada compreensão do todo - o ecossistema precisa ser entendido como um sistema cognitivo de vida.

Neste artigo, em especial, argumentei que a identificação de affordances é crucial para a compreensão de enunciados, uma vez que o significado normalmente não pode ser caracterizado fora da interação (CLARK; CLARK, 1979; KELLY, 1998). Minha ideia básica foi mostrar que o significado não é alcançado apenas através da combinação de palavras e 
outros símbolos abstratos por manipulações sintáticas e probabilísticas. Em vez disso, itens linguísticos precisam ser fundamentados em algum tipo de ação. Mas, da mesma forma que a linguagem não é uma concatenação de palavras, o significado não é uma concatenação de affordances. As affordances devem ser combinadas em um padrão coerente que se sustente em um evento. O cenário básico especificado pela construção de significados limita possíveis combinações de affordances para que os objetivos especificados pela cena sejam alcançados. Se as affordances não podem ser combinadas, a compreensão é lenta e mal sucedida. Trabalhos sobre a combinação de informações lexicais e contextuais na compreensão de sentenças (por exemplo, SWINNEY, 1979; FAUCONNIER, 1999) têm lidado com problemas semelhantes. A combinação de perspectivas defendida aqui nos leva a postular que o processamento cognitivo da compreensão faz uso dos sistemas perceptuais e motores, orientados por affordances de objetos indexados por palavras configuradas em construções gramaticais específicas. O significado passa a ser modelado no cérebro concretamente por meio de circuitos neurais de experiências de percepção e ação.

\section{REFERÊNCIAS}

AZIZ-ZADEH, L.; WILSON, S.; RIZZOLATTI, G.; IACOBONI, M. Congruent Embodied Representations for Visually Presented Actions and Linguistic Phrases Describing Actions, CURBIO, 2006.

BARSALOU, L. W. Perceptual symbol systems. Behavioral and Brain Sciences, 22, 577-660, 1999.

BERGEN, B. K. Louder Than Words: The New Science of How the Mind Makes Meaning. New York, NY: Basic Books, 2012.

BERGEN, B, K.; HEEYON, D. Language-driven motor simulation is sensitive to social context. Proceedings of the 32nd Annual Meeting of the Cognitive Science Society, Austin, TX: Cognitive Science Society, 2010.

BERGEN, B. K.; CHANG, N. Embodied construction grammar in simulation-based language understanding. In: ÖSTMAN, J e FRIED, M. (Ed.). Construction Grammars: cognitive grounding and theoretical extensions. Amsterdam: John Benjamins, 2005.

BERGEN, B. K.; WHEELER, K. Sentence Understanding Engages Motor Processes. In Proceedings of the Twenty-Seventh Annual Conference of the Cognitive Science Society, Austin, TX: Cognitive Science Society, 2005.

BERGEN, B. K.; WHEELER, K. Grammatical aspect and mental simulation. Elsevier: Brain \& Language, 112, p. 150-158, 2010. 
BORODITSKY, Lera. Linguistic relativity. In NADEL, L. (Ed.) Encyclopedia of cognitive science, 917-21. Chichester: John Wiley \& Sons, 2006.

CLARK, E. V.; CLARK, H. H. When nouns surface as verbs. Language, 55, p. 767-811, 1979.

DUQUE, P. H.; COSTA, M.A. Linguística Cognitiva: em busca de uma arquitetura de linguagem compatível com modelos de armazenamento e categorização de experiências. RN: EdUFRN, 2011.

DUQUE, P. H. Discurso e Cognição: uma abordagem baseada em frames. Revista da ANPOLL, v. 1, n. 39, p. 25-48, 2015.

EVANS, V.; BERGEN, B.; ZINGEN, J. The Cognitive Linguistics Reader. London: Equinox, 2007.

FAUCONNIER, G. Mental spaces, language modalities, and conceptual integration. In M. Tomasello (Ed.). The new psychology of language. Mahwah, NJ: Erlbaum, 1999.

FAUCONNIER, G.; TURNER, M. The way we think: conceptual blending and the mind's hidden complexities. New York: Basic Books, 2002.

FILLMORE, C. J.; KAY, P.; O'CONNOR, M. C. Regularity and idiomaticity in grammatical constructions: The case of let alone. Language, 64, p. 501-538, 1988.

FINCHER-KIEFER, R. Perceptual components of situation models. Memory \& Cognition, 29, 336-343, 2001.

GIBSON, J.J. The Theory of Affordances. In SHAW, R.; BRANSFORD, J. (Ed.) Perceiving, Acting, and Knowing. Toward an Ecological Psychology. Hillsdale: NJ, Lawrence Erlbaum Associates, 67-8, 1977.

GIBSON, J. J. The ecological approach to visual perception. New York: Houghton Mifflin, 1979.

GIBSON, J. J. The ecological approach to visual perception. Hillsdale, NJ: Lawrence Erlbaum Associates, 1986.

GLENBERG, A. M.; KASCHAK, M. P. Grounding language in action. Psychonomic Bulletin \& Review, 9, p. 558-565, 2002.

GLENBERG, A. M.; ROBERTSON, D. A. Indexical understanding of instructions. Discourse Processes, 28, p. 1-26, 1999.

HAUK, O.; JOHNSRUDE, I.; PULVERMÜLLER, F. Somatotopic representation of action words in the motor and premotor cortex. Neuron, 41, p. 301-307, 2004.

KELLY, M. H. Phonological biases in grammatical category shifts. Journal of Memory and Language, 27, p. 343-358, 1988.

LAKOFF, G. Linguistic gestalts. In: Regional meeting of the chicago linguistics society, 13, Chicago Linguistics Society, p. 236-287, 1977. 
LAKOFF, G. Women, fire, and dangerous things: What categories reveal about the mind. Chicago: Univ. of Chicago Press, 1987.

STANFIELD, R. A.; ZWAAN, R. A. The effect of implied orientation derived from verbal context on picture recognition. Psychological Science, 12, 153-156, 2001.

SWINNEY, D. A. Lexical access during sentence comprehension: (Re)consideration of context effects. Journal of Verbal Learning and Verbal Behavior, 18, p. 645-659, 1979.

ZWAAN, R. A.; STANFIELD, R. A.; YAXLEY, R. H. Language comprehenders mentally represent the shape of objects. Psychological Science, 13, 168-171, 2002.

Recebido em 2 de março de 2015.

Aceito em 1 de maio de 2015. 